\title{
放射線治療における精度管理運用 web システムの開発
}

\author{
岡本裕之 ${ }^{1}$ 望月寿彦 ${ }^{2}$ 横山和利 ${ }^{1} \quad$ 脇田明尚 ${ }^{1}$ 中村哲志 $^{1} \quad$ 植木平八 ${ }^{2}$ \\ 塩沢惠子 ${ }^{2}$ 佐々木浩二 ${ }^{2}$ 布施雅史 ${ }^{1} \quad$ 阿部容久 $^{1}$ 伊丹 純 $^{1}$ \\ ${ }^{1}$ 国立がん研究センター中央病院放射線治療科 \\ 2 株式会社アドイン研究所
}

\section{緒 言}

昨今, 強度変調放射線治療をはじめとする高精度放 射線治療のプロセスは, 複雑化の一途を辿っており, 多くの職種が切れ目のない連携を基にして遂行されて いる. このような状況の中, 放射線治療の質と安全を恒 常的に維持・管理するためには，放射線治療に従事する すべてのスタッフが共通のリスク意識をもち, 組織的な 体制による精度管理の実行が必要不可欠である。しか し大規模病院においては, スタッフや装置の数が多く, スタッフ個々が共通のリスク意識をもち, 統一された精 度管理手法を実行することは容易ではない. 放射線治 療管理に携わるわれわれとしては常にあらゆる手段を
模索し, 実現に向けて努力する必要がある。本研究で はその実現に向けた一つの手段として, 情報共有の強 化が期待できる精度管理運用 web システムの開発を目 的とした. 本研究で言う精度管理運用 web システムと は, 放射線治療の精度管理結果などに特化した, 情報 共有の強化が期待できるシステムを指す。本報告で は，どの施設でも容易に作成することが可能な，HTML (HyperText Markup Language)をベースとした手法とさ らに発展的な手法である PHP(Hypertext Preprocessor) 言語などのサーバサイドスクリプトを用いた手法ついて 言及する。この精度管理運用 web システムに必要とさ れる機能としては, I. 精度管理結果や報告書, 作業マ

\section{Development of Quality Assurance/Quality Control Web System in Radiotherapy}

Hiroyuki Okamoto, ${ }^{1 *}$ Toshihiko Mochizuki, ${ }^{2}$ Kazutoshi Yokoyama, ${ }^{1}$ Akihisa Wakita, ${ }^{1}$ Satoshi Nakamura, ${ }^{1}$ Heihachi Ueki, ${ }^{2}$ Keiko Shiozawa, ${ }^{2}$ Koji Sasaki, ${ }^{2}$ Masashi Fuse, ${ }^{1}$ Yoshihisa Abe, ${ }^{1}$ and Jun Itami ${ }^{1}$

${ }^{1}$ Radiation Oncology Division, National Cancer Center Hospital

${ }^{2}$ AdIn Research Inc.

Received June 12, 2013; Revision accepted September 17, 2013

Code No. 920

\section{Summary}

Our purpose is to develop a QA/QC (quality assurance/quality control) web system using a server-side script language such as HTML (HyperText Markup Language) and PHP (Hypertext Preprocessor), which can be useful as a tool to share information about QA/QC in radiotherapy. The system proposed in this study can be easily built in one's own institute, because HTML can be easily handled. There are two desired functions in a QA/QC web system: (i) To review the results of QA/QC for a radiotherapy machine, manuals, and reports necessary for routinely performing radiotherapy through this system. By disclosing the results, transparency can be maintained, (ii) To reveal a protocol for QA/QC in one's own institute using pictures and movies relating to QA/QC for simplicity's sake, which can also be used as an educational tool for junior radiation technologists and medical physicists. By using this system, not only administrators, but also all staff involved in radiotherapy, can obtain information about the conditions and accuracy of treatment machines through the QA/QC web system.

Key words: quality assurance (QA), quality control (QC), radiotherapy, HyperText Markup Language (HTML), Hypertext Preprocessor (PHP)

*Proceeding author 


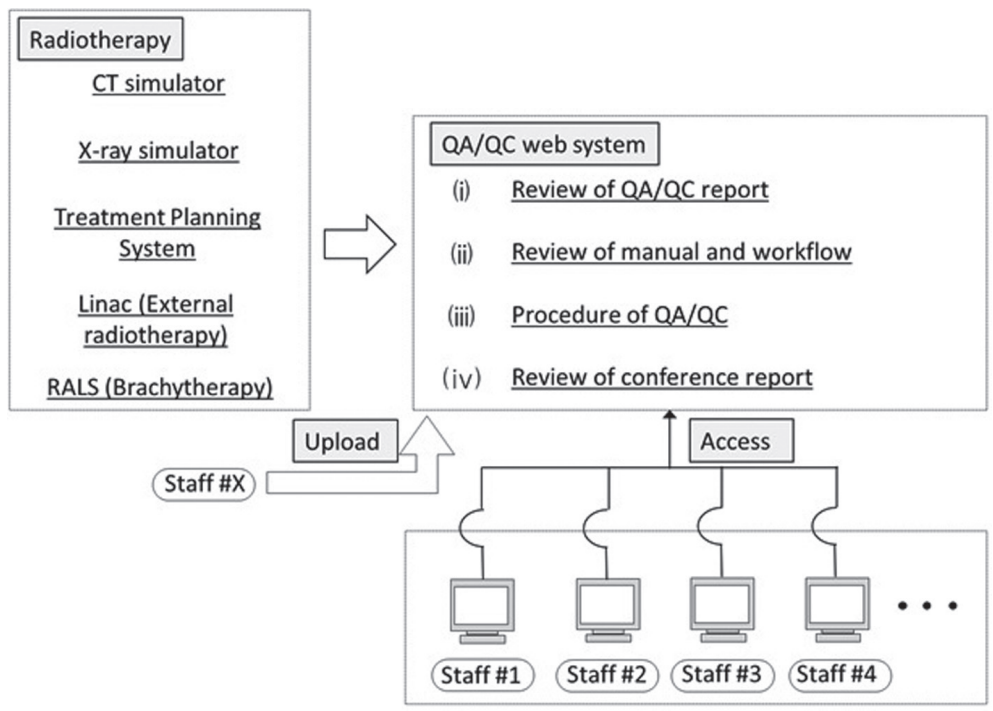

Fig. 1 Schematic of QA/QC web system developed in this study.

ニュアルなどが閲覧できる機能，II. 精度管理の手法な どを写真や動画を用いて解説した機能，が挙げられ る. I. に関して，放射線治療関連機器の精度管理は, 個人の活動ではなく放射線治療部内の活動として位置 づけられる必要があり, 本システムを通して, 精度管理 実施者だけではなく放射線腫瘍医も含めた全スタッフ が治療関連機器の品質管理状況を把握することができ る. II. に関しては，精度管理手技の統一と若手スタッ フへの教育的ツールとしての活用にも期待できる.

\section{1. 方 法}

\section{1-1 精度管理運用 web システム}

現在市販されている精度管理運用に関するソフトと しては, ATLAS-QA(SUN NUCLEAR 社)1), RIT113 (RIT 社) ${ }^{2)}$ ，eQA(Modus Medical Device 社) ${ }^{3)}$ な゙が挙 げられる。それぞれが特徵的な機能を有しているが， たとえばATLAS-QA ${ }^{1)}$ では，線量測定器との連携が行 え, 線量プロファイルの不変性試験などの試験結果を データベースとして記録することができる。さらには RIT1132)では，2009年に刊行された放射線治療装置 の品質管理に関するガイドライン AAPM(American Association of Physicists in Medicine) Task Group 142 のコンセプトを基に設計され，基準值の設定など各施 設の照射技術に対応した分析法が作成可能である。 $\mathrm{eQA}^{3)}$ においては, SQL(Structured Query Language) データベースと交信することによって EPID(Electric Portal Imaging Device) 画像を自動で取得・解析し, 試験 結果をデータベースとして管理することができる。これ らのソフトで共通な点は, 精度管理の結果を一元管理 し，スタッフであれば誰でも過去の精度管理結果などを
自由に閲覧することができることである，本研究で開発 した精度管理運用 web システムは，上記のような測定 器との連携や解析機能などはないものの, 情報共有の 強化に特化した閲覧機能などを設けており,さらに HTML や PHP 言語などのサーバサイドスクリプトで構 成されているため，ある程度コンピュータ言語に精通し ているスタッフがいれば，自施設に対応したシステムを 容易に導入することが可能である。

\section{1-2 機能と運用手順}

Fig. 1 に，精度管理運用 web システムの運用を図示 化した，各担当者が共有すべき報告書や精度管理結果 などを精度管理運用 web システムがインストールされ ている管理用パソコン[図中では QA/QC (quality assurance/quality control)web system]にアップロードし，他 のスタッフが閲覧する. HTMLの場合には管理者が ソースファイルを編集し，項目を追加してリンクを生成 させる.PHP言語を使用している場合にはユーザの更 新したデータをデータベースに保存し，他のユーザが閲 覧した時に更新データをリアルタイムに確認できる。ど のPCからも情報を閲覧することができ，放射線治療部 内での円滑な情報共有が可能でありながら，七キュリ テイ上の観点から使用制限を設定することもできる。ま た報告書や精度管理記録など一元管理することがで き，担当スタッフが異動した場合などに発生する情報 損失を最小限に抑えることができる。

本研究で開発した精度管理運用 web システムの四つ の機能について説明する[Fig. 1 では機能 $(i) 〜(i v) に$ 該 当].（i）: 精度管理結果の閲覧機能に関しては, 放射線 治療装置だけではなく放射線治療システムに関係する 


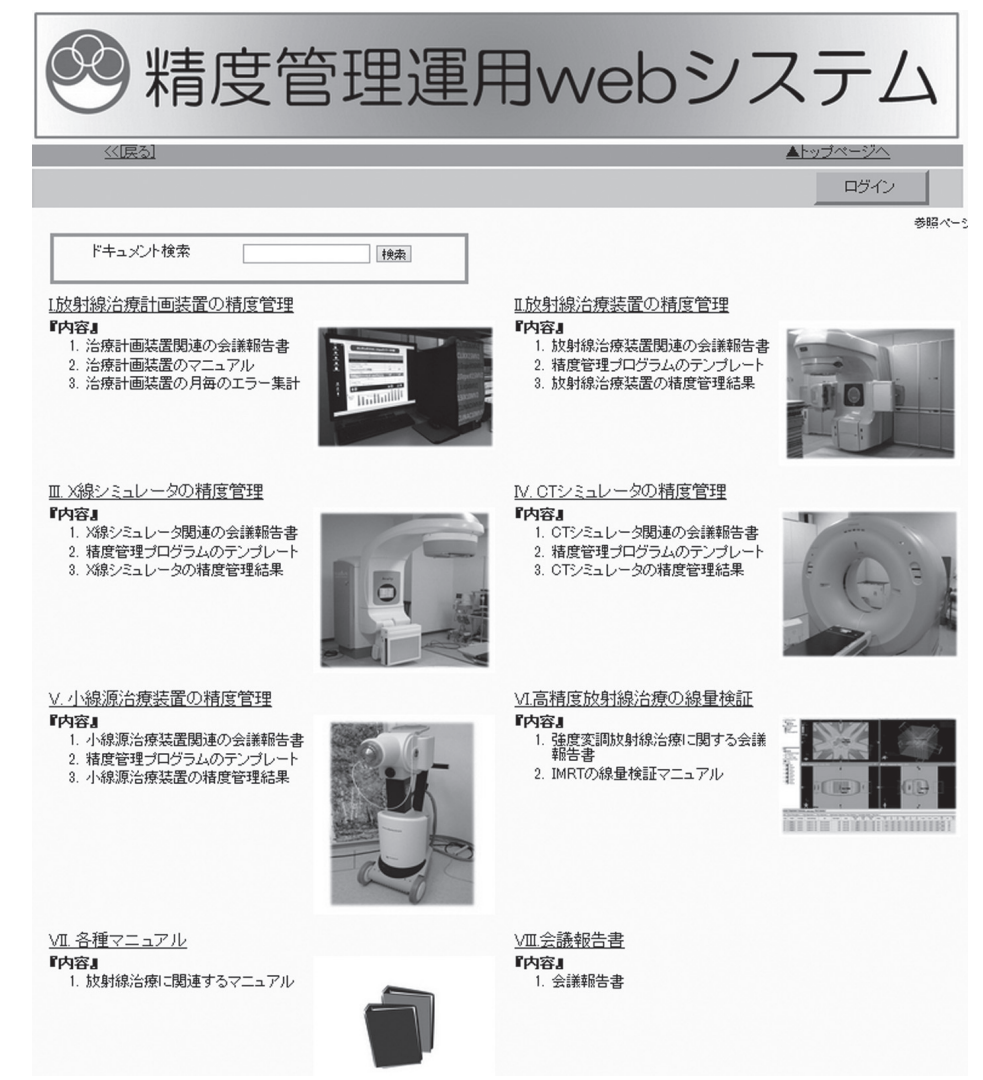

Fig. 2 Overview of QA/QC web system developed in this study.

すべての機器を対象にする必要がある．たとえば当院 では, 放射線治療装置のほかに, 計画 CT(computed tomography)シミュレータ, X 線シミュレータ, 放射線 治療計画装置，小線源治療装置などを対象としてい る. 品質管理担当者だけでなく放射線腫瘍医をはじめ とする全スタッフが, 治療装置関連機器の品質管理状 況を一つのシステムから知ることができる。また機器ご とに共通のインターフェイスを構築することによってス タッフの理解が容易となる。 また対内的ではあるが放射 線治療部内で精度管理結果を開示することで，精度管 理実施の有無や精度管理結果に対しての妥当性に関し ても，第 3 者の視点から評価することができる。（ii）: 放射線治療品質管理機構では，過去に起きた放射線治 療における医療事故の教訓から，臨床現場においては 精度管理の具体的措置を含めた作業マニュアルの必要 性を提言している5)。この作業マニュアルには，放射線 治療の実施状況に応じた日々の更新が伴う。本研究で 開発する精度管理運用 web システムには，治療プロセ スで必要となるすべての作業マニュアルを一元管理 し，新しい作業マニュアルを日々アップロードすること で，全スタッフが最新版を閲覧することができる（iii）: 複数の装置を使用している病院では, スタッフ間で精度 管理手法を統一することは重要である。ここでは, 精度
管理の手法に関して，写真や動画を用いて解説する ページを設けている，さらにこの機能は若手の診療放 射線技師や医学物理士のための教育的ツールにも活用 できる。（iv）：当院では，全スタッフが参加する全体会 議を毎月開催し, 臨床的・物理的，あるいは運用に関し ての検討すべき事項を議論している，本研究が開発す る精度管理運用 web システムには，会議で使用する資 料・報告書なども一元化するようにし，資料・報告書の 共有を図っている.

\section{2. 結 果}

Fig. 2 に, 本研究で開発した精度管理運用 web シス テムの概観を示す．Fig. 2 では，PHP 言語を用いた手 法であるが，HTMLを用いた場合でも同様の仕様を構 築することが可能である，図に示されているように，放 射線治療に関係するすべての機器が対象であり，それ ぞれのカテゴリで Fig. 1 に示されている機能(i)〜 (iv)が 搭載されている。またwebサーチエンジンとして Apache Licenseによって開発されているオープンソース ソフトウェア，Apache Nutch ${ }^{\mathrm{TM}}$ を利用している。この サーチエンジンを利用することによって，これまで報告 したドキュメントの内容までを範囲とするキーワード検 索が可能となる(Fig. 2 ではドキュメント検索を指す). 


\section{III. 放射線治療装置の精度管理の結果}

平成21年7月 平成22年6月 の検証結果

\begin{tabular}{|l|c|c|c|c|c|c|c|c|c|c|c|c|c|}
\hline \multicolumn{1}{|c|}{ 装置/月 } & 7月 & 8月 & 9月 & 10月 & 11月 & 12月 & 1月 & 2月 & 3月 & 4月 & 5月 & 6月 & 年毎の精度管理 \\
\hline 9番治療装置の検証結果 & 実施 & 実施 & 実施 & 実施 & 実施 & 実施 & 実施 & 実施 & 実施 & 実施 & 実施 & 実施 & 実施 \\
\hline 10番治療装置の検証結果 & 実施 & 実施 & 実施 & 実施 & 実施 & 実施 & 実施 & 実施 & 実施 & 実施 & 実施 & 実施 & 実施 \\
\hline 13番治療装置の検証結果 & 実施 & 実施 & 実施 & 実施 & 実施 & 実施 & 実施 & 実施 & 実施 & 実施 & 実施 & 実施 & 実施 \\
\hline 14番治療装置の検証結果 & 実施 & 実施 & 実施 & 実施 & 実施 & 実施 & 実施 & 実施 & 実施 & 実施 & 実施 & 実施 & 実施 \\
\hline
\end{tabular}

平成22年7月 平成23年6月 の検証結果

\begin{tabular}{|l|c|c|c|c|c|c|c|c|c|c|c|c|c|}
\hline \multicolumn{1}{|c|}{ 装置/月 } & 7月 & 8月 & 9月 & 10月 & 11月 & 12月 & 1月 & 2月 & 3月 & 4月 & 5月 & 月月 & 年毎の精度管理 \\
\hline 9番治療装置の検証結果 & 実施 & 実施 & 実施 & 未実施 & 実施 & 実施 & 未実施 & 実施 & 実施 & 実施 & 未実施 & 実施 & 実施 \\
\hline 10番治療装置の検証結果 & 実施 & 実施 & 未実施 & 実施 & 実施 & 未実施 & 実施 & 実施 & 実施 & 未実施 & 実施 & 実施 & 実施 \\
\hline 13番治療装置の検証結果 & 実施 & 実施 & 未実施 & 実施 & 実施 & 未実施 & 実施 & 未実施 & 実施 & 実施 & 実施 & 実施 & 実施 \\
\hline 14番治療装置の検証結果 & 未実施 & 実施 & 実施 & 未実施 & 未実施 & 実施 & 未実施 & 実施 & 実施 & 実施 & 未実施 & 実施 & 実施 \\
\hline
\end{tabular}

\section{平成23年7月 平成24年6月 の検証結果}

\begin{tabular}{|l|c|c|c|c|c|c|c|c|c|c|c|c|c|}
\hline \multicolumn{1}{|c|}{ 装置/月 } & 7月 & 8月 & 9月 & 10月 & 11月 & 12月 & 1月 & 2月 & 3月 & 4月 & 5月 & 6月 & 年毎の精度管理 \\
\hline 9番治療装置の検証結果 & 実施 & 実施 & 実施 & 未実施 & 実施 & 未実施 & 未実施 & 実施 & 実施 & 実施 & 実施 & 実施 & 実施 \\
\hline 10番治療装置の検証結果 & 実施 & 実施 & 未実施 & 実施 & 実施 & 未実施 & 実施 & 実施 & 実施 & 実施 & 未実施 & 実施 & 実施 \\
\hline 13番治療装置の検証結果 & 実施 & 実施 & 未実施 & 実施 & 実施 & 未実施 & 未実施 & 未実施 & 未実施 & 未実施 & 未実施 未実施 & 実施 \\
\hline 14番治療装置の検証結果 & 実施 & 実施 & 実施 & 実施 & 未実施 & 実施 & 実施 & 未実施 & 未実施 & 実施 & 実施 & 実施 & 未実施 \\
\hline
\end{tabular}

Fig. 3 Record of QA/QC of treatment machine corresponding to function (i) in Fig. 1.

たとえば，“ガントリ”と検索すると，過去にガントリ関 連で報告した資料やガントリの精度管理結果などがリ ストアップされる。

Fig. 3 は当院の精度管理の実施記録の一部を示して いる[Fig. 1 では(i)Review of QA/QC reportに相当]. 図 に示されているように精度管理運用 web システムを利 用することによって，対内的ではあるが放射線治療部内 で精度管理実施の有無を開示することで透明性が確保 できる．また精度管理結果も掲載することによって，第 3者の視点から結果の妥当性について評価することがで きる.

Fig. 4 に当院の精度管理結果の例を示す[Fig. 1 では (i) Review of QA/QC reportに相当]. 当院では, Fig. 3 の実施項目を選択すると, 図に示されるように精度管理 結果が PDF(Portable Document Format)形式で表示さ れる。 これはHTMLを用いても可能である。運用手順 としては, 精度管理実施担当者が結果を PDF 形式に変 換して, ファイルをアップロードする(Fig. 5).

また将来的には, Fig. 6 に示されているように, タブ レッド型端末を用いた運用についても検討している.

Fig. 6 では, タブレット型端末を用いることで, 過去の 精度管理結果を参考にしながら精度管理を実施してい る. Fig. 7 には，写真や動画を用いた精度管理法の解説 を示している[Fig. 1では(iii) Procedure of QA/QCに相 当]. 具体的に精度管理手法を写真や動画を用いて解説 することによって，スタッフ間での手技統一が図れる.

\section{3. 考察}

本研究で開発した精度管理運用 web システムは, HTML や PHP 言語などのサーバサイドスクリプトを基 に構築されているため, コンピュータ言語にある程度精 通しているスタッフであれば，自施設の状況に対応した 精度管理運用 web システムを構築することが可能であ る。また一度構築を行えば, 資料や精度管理結果など を半永久的に一元管理できる利点を有する。また HTML のハイパーリンク機能を用いることによって，他 の web システムへの情報参照が容易になる。 また近 年, HTML や PHP 言語などのオープンソースに打いて もメンテナンスがしっかりと行われているソフトウェア が増えてきている.オープンソースのプログラムはライ センスの縛りが多いが，そのライセンスの範囲で活用す れば, 安価に高度なクライアントサーバシステムを構築 することが可能である。これまでは，解析者ごと，ある いは機器ごとに試験結果などを管理している場合が少 なくなく, 時にはスタッフの転勤やローテーションなど の原因によって情報共有することが困難な状況に直面 してきた。また会議で使用する報告書に関しても同様 で, 紙媒体で配布されているため, 資料の紛失や, 久 タッフが入れ替わることによる情報共有の欠落が問題 視されてきた，これらの精度管理運用 web システムを 活用することで, 精度管理全体にかかわるデー夕を半 永久的に一元管理することが可能となり，得られた知見 を後世のスタッフへ正しく提供することが可能となる. 


\section{月毎の精度理頊目 - 国立がん研究センター中央病院 一}

\begin{tabular}{|c|c|c|c|c|c|c|}
\hline (6)フロントポインタを用いたコリメーター回転精度 & 許容値 & \multicolumn{3}{|c|}{ 検証結果 } & 判定 & 時間 \\
\hline \multirow{4}{*}{ 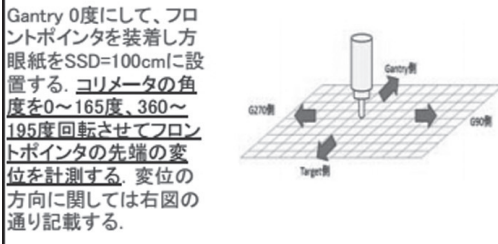 } & \multirow{4}{*}{ $\pm 2 \mathrm{~mm}$} & \multirow{2}{*}{$0 \sim 165$ 度 } & Lateral方向 & OK & O & \multirow{4}{*}{ 5分 } \\
\hline & & & Long方向 & OK & 0 & \\
\hline & & \multirow{2}{*}{$360 \sim 195$ 度 } & Lateral方向 & OK & 0 & \\
\hline & & & Long方向 & $\mathrm{G}$ 側に $=0.7 \mathrm{~mm}$ & 0 & \\
\hline
\end{tabular}

\begin{tabular}{|c|c|c|c|c|c|c|}
\hline (7フロントポインタを用いた寝台回転精度 & 許容値 & \multicolumn{3}{|c|}{ 検証結果 } & 判定 & 時間 \\
\hline \multirow{4}{*}{ 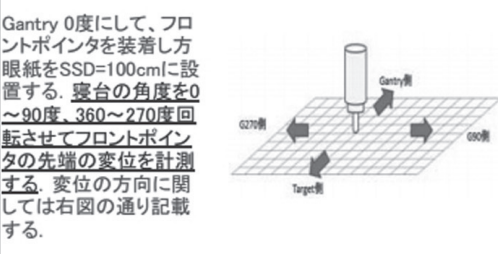 } & \multirow{4}{*}{ $\pm 2 \mathrm{~mm}$} & \multirow{2}{*}{ 0 90度 } & Lateral方向: & OK & O & \multirow{4}{*}{ 3分 } \\
\hline & & & Long方向: & OK & 0 & \\
\hline & & \multirow{2}{*}{$360 \sim 270$ 度 } & Latera|方向: & $\mathrm{G} 90^{\circ}$ 側に $=0.5 \mathrm{~mm}$ & 0 & \\
\hline & & & Long方向: & OK & 0 & \\
\hline
\end{tabular}

\begin{tabular}{|c|c|c|c|c|c|c|}
\hline 8)金尺を用いた寝台座標の移動距離の確認 & 許容値 & \multicolumn{3}{|c|}{ 検証結果 } & 判定 & 時間 \\
\hline \multirow{8}{*}{ 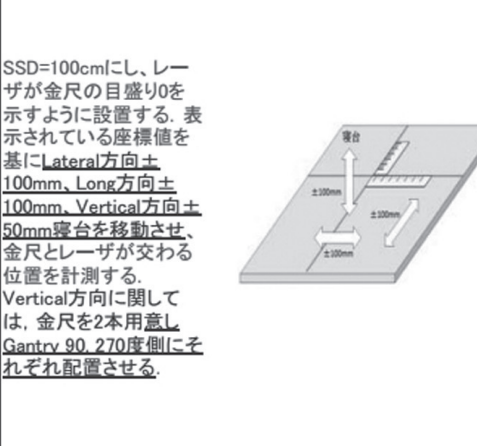 } & \multirow{8}{*}{ $\pm 2 \mathrm{~mm}$} & G90方向に柇 & $+100 \mathrm{~mm}$ & $100 \mathrm{~mm}$ & O & \multirow{8}{*}{ 10分 } \\
\hline & & G270方向に & $+100 \mathrm{~mm}$ & $100 \mathrm{~mm}$ & O & \\
\hline & & \multicolumn{2}{|c|}{$\begin{array}{c}\text { Gun側方向に移動 } \\
+100 \mathrm{~mm}\end{array}$} & $100 \mathrm{~mm}$ & O & \\
\hline & & \multicolumn{2}{|c|}{$\begin{array}{c}\text { Target側方向に移動 } \\
+100 \mathrm{~mm}\end{array}$} & $100.05 \mathrm{~mm}$ & $\mathrm{O}$ & \\
\hline & & \multirow{2}{*}{$\begin{array}{l}\text { 天井方向 } \\
+50 \mathrm{~mm}\end{array}$} & G90側: & $50 \mathrm{~mm}$ & O & \\
\hline & & & G270側: & $50 \mathrm{~mm}$ & O & \\
\hline & & \multirow{2}{*}{$\begin{array}{l}\text { 床方向 } \\
+50 \mathrm{~mm}\end{array}$} & G90僛: & $50 \mathrm{~mm}$ & 0 & \\
\hline & & & G270側： & $50 \mathrm{~mm}$ & 0 & \\
\hline
\end{tabular}

Fig. 4 Review of QA/QC report corresponding to function (i) in Fig. 1.

\section{I. 放射線治療装置関連の会議報告書}

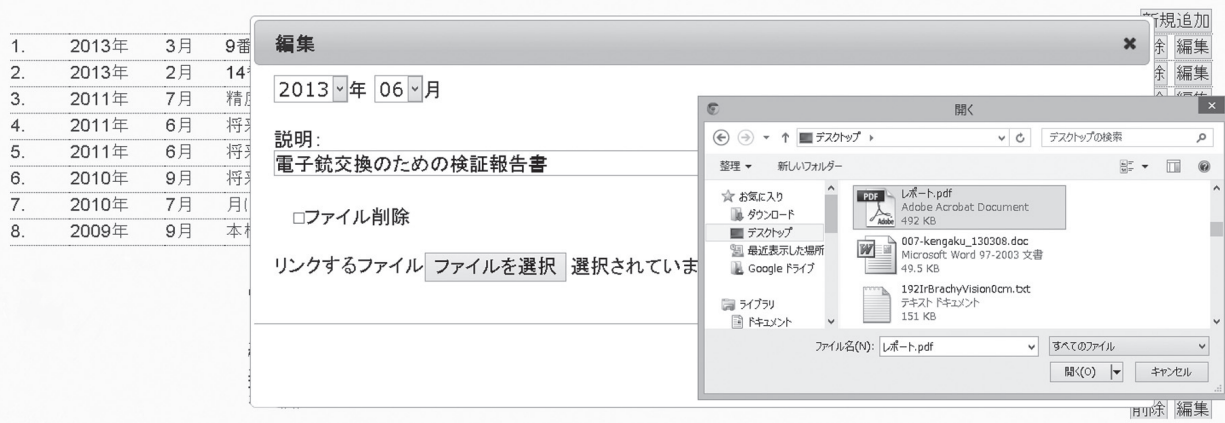

Fig. 5 Upload of report.

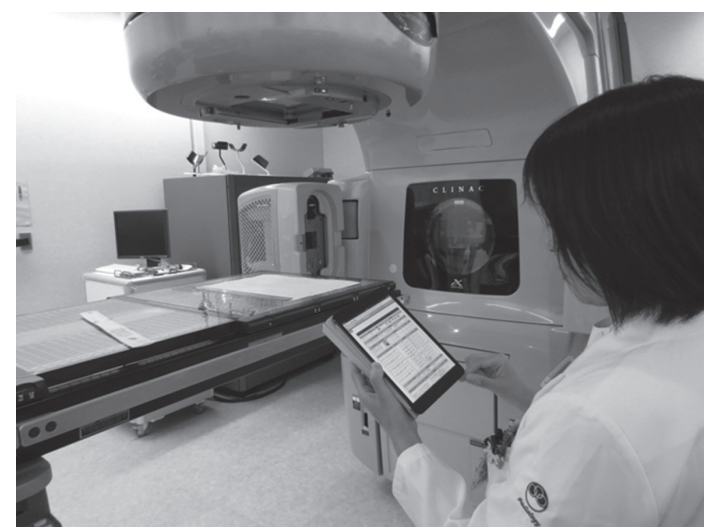

Fig. 6 Use of QA/QC web system using tablet device. 


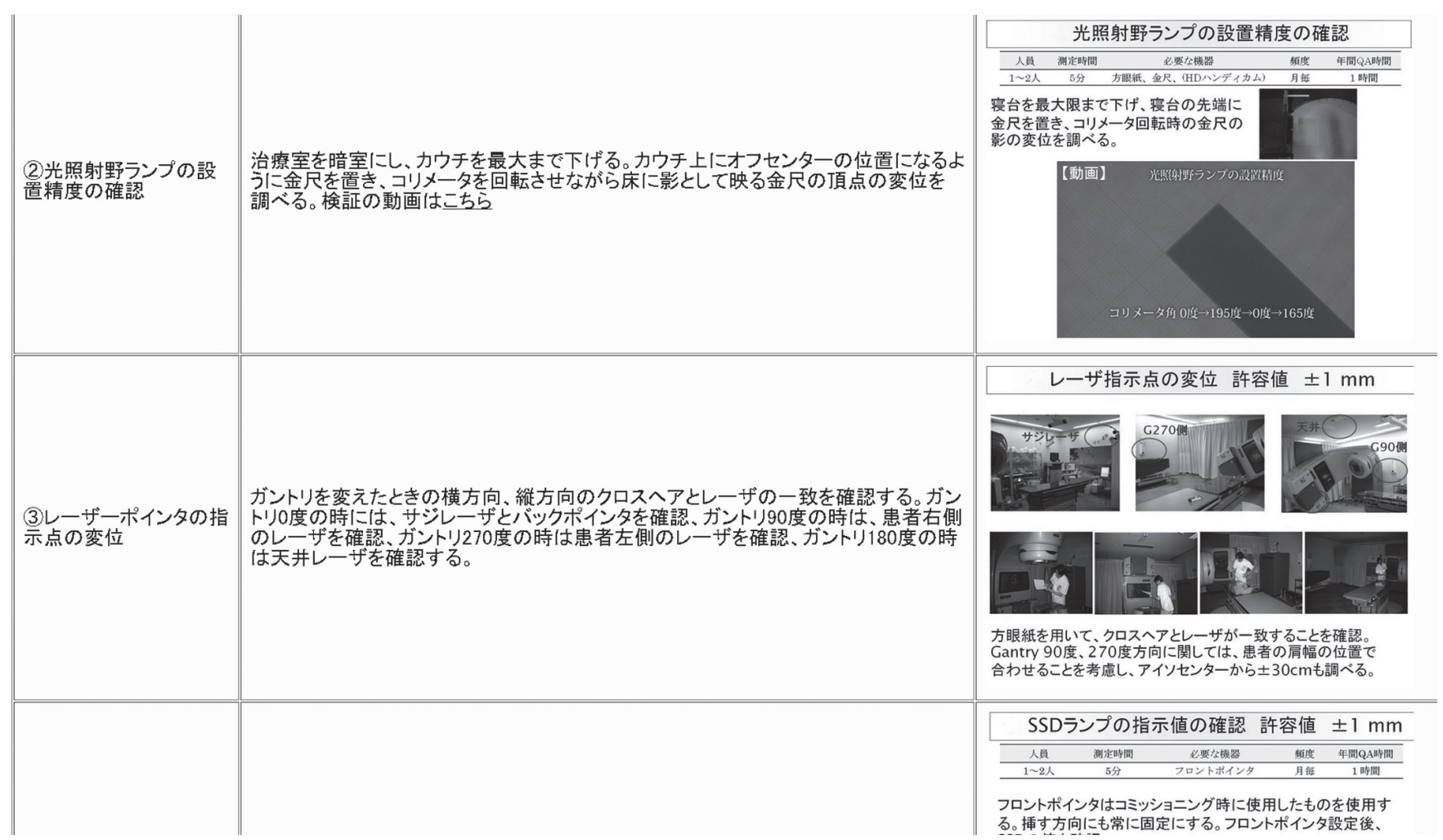

Fig. 7 Manual of QA/QC using pictures and movies corresponding to function (iii) in Fig. 1.

本研究で開発した精度管理運用web システムは, 2011 年 10 月にHTMLをベースとして臨床導入され た. 2013 年 1 月には PHP 言語をベースとして再設計さ れ今日まで運用されている。延べ約 2 年, 臨床運用を 行ってきた. 本システムの有効性について定量的評価 は困難であるが，筆者の使用経験を次に述べる。放射 線治療における精度管理で重要な点は, どのスタッフ が実施しても同じ精度管理手法が行え, 統一された評 価基準をもって実施できることである，当院では放射線 腫瘍医が 6 名, レジデント 6 名, 診療放射線技師が 13 名, 医学物理士が 3 名, 治療専属看護師 3 名とス夕ッ フが非常に多い，精度管理運用 web システムがない以 前は，装置ごとで精度管理結果などを管理していたた め, 精度管理結果などを含む多くの情報を，放射線治 療に従事するすべてのスタッフに効率よく共有すること が困難であった，さらに当院では，放射線治療装置が 4 台，小線源治療装置が 1 台と多くの機器を所有してい るため, 導入以前は, 装置ごと, スタッフごとで精度管 理手技にばらつきがみられ，精度管理結果に対する評 価基準も統一されていなかった。本研究で開発した精 度管理運用 web システムを導入したことによって，装 置・スタッフ間で生じていた手技や判断基準の違いが明 確になり，その低減に努めることができたと考える.
放射線治療関連機器の精度管理は, 個人の活動の範 囲で実施するものではなく，放射線治療部内の活動の 範囲として認識される必要がある。そのため, 精度管 理実施者は精度管理結果を記録・開示し，放射線腫瘍 医も含めたすべてのスタッフが治療関連機器の品質管 理状況を把握することが重要となる，特に放射線治療 は，複雑なプロセスの中で多くの職種の連携を基に遂 行されているため, 各プロセスで透明性を確保し, “見 える化(可視化)”6)に向けて努力する必要がある.

放射線治療の質・安全性を維持するためには, 放射線 治療部内で安全を優先とした考え(安全文化 ${ }^{7,8)}$ )を根付 かせることが重要である。技術革新が日進月歩する 中，新しい機能や技術に注目が先行してしまいがちに あるが，管理者であるわれわれはそこに潜むリスクを冷 静に見定め, 本当に安全な放射線治療ができているか どうか自問自答する機会をもつ必要がある。またこの意 識改革は個々のレベルでは限界があり, 個人のレベル を超えて集団としての共通認識(文化)の構築が求めら れる。結果として, 放射線治療部全体の取り組みと連 携を経て, この安全文化が放射線治療部内で生み出さ れる. Fig. 1，2 に示すように，本研究で開発した精度 管理運用 web システムが, この安全文化構築への一助 となることを確信している. 


\section{4. 結 語}

放射線治療の質と安全を恒常的に維持するために は，放射線治療に従事するすべてのスタッフが共通の リスク意識をもち，統一された精度管理手法を実行す ることが大切である。その実現に向けた一つの手段とし て, 本研究で開発した精度管理運用 web システムが有 効に利用できると考える.

\section{謝 辞}

本研究の一部は，がん研究開発費 23-A-13「伊丹班： 安全で高精度の放射線治療を実現する放射線治療体制 に関する研究」の助成を受けたものです。またこの場を お借りしまして，国立がん研究センター中央病院放射線 治療科のスタッフにご協力いただいたことを感謝いたし ます。

\section{参考文献}

1) ATLAS-QA, manufactured by SUN NUCLEAR corporation at http://www.sunnuclear.com/home.asp (accessed 2013-419).

2) RIT113, manufactured by Radiological Imaging Technology, Inc. at http://www.radimage.com/ (accessed 2013-4-19).

3) eQA, manufactured by Modus Medical Devices Inc. at http://modusmed.com/ (accessed 2013-4-19).

4) Klein EE, Hanley J, Bayouth J, et al. Task Group 142 report: quality assurance of medical accelerators. Med Phys 2009; 36(9): 4197-4212.

5）放射線治療における医療事故防止のための安全管理体制の
確立に向けて(提言)。放射線治療品質管理機構. 2007. at http://www.qcrt.org/report2.pdf(accessed 2013-4-19).

6) 岡本裕之 監, 黒岡将彦, 宮浦和徳, 他. 詳説 放射線治療 の精度管理と測定技術. 東京: 中外医学社, 2012.

7) International Nuclear Safety Advisory Group. Safety culture. Safety series no. 75-INSAG-4. Vienna: IARA; 1991.

8) International Commission on Radiological Protection. ICRP Publication 112. Preventing accidental exposures from new external beam radiation therapy technologies. Ann ICRP. 2009; 39: 1-86. 